\title{
MANIFESTATION OF EFFECT OF FLUCTUATING ASYMMETRY OF BILATERAL TRAITS OF TOMATO GROWING IN INDUSTRIAL GREENHOUSES
}

\author{
Sergey Rakutko ${ }^{1}$, Ina Alsina ${ }^{2}$, Ansis Avotins ${ }^{3}$, Kristina Berzina ${ }^{3}$ \\ ${ }^{1}$ Institute for Engineering and Environmental Problems in Agricultural Production, Russia; \\ ${ }^{2}$ Latvia University of Life Sciences and Technologies, Latvia; ${ }^{3}$ Riga Technical University, Latvia \\ sergej1964@yandex.ru
}

\begin{abstract}
Sustainable plant development, i.e. maintenance of its phenotype in conditions of changing environmental parameters or genetic deviations, is realized by a set of mechanisms, generally characterized by developmental stability. The most striking manifestation of the stability of the development of the biological object at the macro level is the effect of fluctuating asymmetry (FA). The lighting conditions, along with other environmental factors, affect both the productivity of the plant and the stability of its development. The issues that remain scarcely studied are the influence of lighting conditions and plant variety on the FA level. One of the widely used and informative parameters is the chlorophyll content in plant leaves and their size. The aim of the study is to confirm the hypothesis of the effect of differences in the light quality and plant variety on the level of FA of the symmetrical plant structures. The object of the study is the leaves of tomato plants grown in an industrial greenhouse. The measurements were carried out in the greenhouse of Mezvidi, Latgalia, for three variants: tomato variety orange Bolzano F1 grown under high-pressure sodium lamps (HPS) and LED sources, and the red Encore F1 grown under HPS. As a result of the experiments, the presence of a significant asymmetry of the bilateral structures of tomato leaves was detected by their size and chlorophyll content. The fluctuating nature of asymmetry is proved. It was revealed that the influence of the type of the light source and tomato variety on FA on the basis of certain traits is multidirectional. For the tomato variety Bolzano, the level of FA on the basis of the leaflet size is $66 \%$ higher under HPS compared to the LED, and on the basis of the chlorophyll content does not depend on the type of the light source. For HPS the level of FA on the basis of the leaflet size is $24 \%$ higher at Bolzano compared to Encore, and on the basis of the chlorophyll content, it is $28 \%$ lower.
\end{abstract}

Keywords: developmental, stability, plant, lighting, energoecology.

\section{Introduction}

Effective cultivation of plants in artificial conditions is possible only using the indoor plant lighting technology with supplemental light sources. Light is one of the factors that affect the concentration of phytochemical compounds [1]. Sustainable plant development, i.e. maintenance of its phenotype in conditions of changing environmental parameters or genetic deviations is realized by a set of mechanisms, generally characterized by stability of development. The most striking manifestation of the stability of the development of the biological object at the macrolevel is the fluctuating asymmetry (FA), which consists in minor and random deviations of the parameters of bilateral (mirror) traits. It was revealed that the relationship between stress factors and the stability of development is not obvious. A number of researchers note an increase of the FA level under stress, while others do not confirm a statistically significant relationship [2]. Under favourable environmental conditions, organisms experience less stress, which increases the stability of their development and leads to a smaller value of FA. The lighting conditions, like other environmental factors, affect both the productivity of the plant and the stability of its development.

The available studies on the influence of the parameters of illumination on the FA level are few. It is revealed that the lighting conditions in the process of plant development can be the direct cause of the increase in the asymmetry of the leaf [3]. Thus, for wild mustard (Sinapsis arvensis) stressful environmental conditions lead to an increase in the FA level for all traits, but only slightly change the symmetry of the petal, while changes in the symmetry of leaves and fruits are much stronger [4]. There are differences in the morphological characteristics of the leaves and flowers of dwarf iris (Iris pumila) at different light intensities in the population as a result of adaptation to local environmental conditions [5]. Lack of light contributes to a serious decrease in the productivity of the Pyrine oak seedlings (Quercus pyrenaica), the FA level was also higher under shading conditions, compared to plants in sunlight [6]. But, on the other hand, the FA level in the neotropical shrubby species of Banisteriopsis campestris growing on a sunny spot was higher and there is a correlation with the productivity of nectar [7]. The asymmetry distribution pattern depends on the lighting level. The Bauhinia brevipes revealed a normal pattern of distribution in plants in sunlight and antisymmetry in 
shaded plants. At the same time, the asymmetry and leaf area were $5 \%$ and $26.8 \%$ higher respectively in plants in the shade, which is a compensation for low absorption of light and indicates stress [8].

Thus, the FA level can be used to predict changes in the development of plants as a measure of environmental stress. At the same time, the FA level is minimal only under optimal environmental conditions and increases under any stress conditions. Assuming that the nonoptimality of the parameters of the irradiation affecting the plants is a stress factor, it becomes possible to adopt the FA level as an indicator of the state of the plant, by which it is possible to evaluate the efficiency and ecological compatibility of the plant growing process.

This approach is widely used in plant cultivation in natural conditions; however, for artificial cultivation conditions the stability of plant development issues has not been adequately studied.

In the laboratory of energy and ecology issues of the IEEP, a number of studies of the FA level of the leaf parsley leaf (Petroselinum tuberosum), grown for grazing under otherwise equal conditions under radiation sources with different light quality, were carried out. The relationship between the indicator of the usefulness of the radiation flux and the FA level is established [9].

Studies have shown that large values of the FA level are observed under conditions less favourable for plants, therefore, the FA level can be a diagnostic parameter of the acceptability of the light quality of radiation sources in the indoor plant lighting for the grown culture [10]. A technique for assessing the stability of plant development in indoor plant lighting with the FA level is made [11]. The obtained experimental data and techniques can be used as a part of the energy-ecological audit of indoor plant lighting $[12 ; 13]$.

One of the widely used and informative parameters is the chlorophyll content in plant leaves and their geometric dimensions. The aim of the study was to confirm the hypothesis of the effect of differences in the variety and quality of irradiation on the FA level of bilateral traits of symmetrical plant structures. The object of research is the leaves of tomato grown in an industrial greenhouse.

\section{Materials and methods}

As a species, the example of which the influence of lighting conditions on the indicator of fluctuating asymmetry of bilateral traits was investigated, tomato was selected. Currently, tomato is one of the main vegetable crops around the world [14]. It is grown both in tropical, subtropical and temperate areas [15]. Light is the main environmental factor affecting tomato growth and biomass production. Insufficient intensity of light or its unsatisfactory spectral composition worsens the growth and development of tomato seedlings, especially during the development of the first inflorescence, which reduces the quality of seedlings [16]. In northern latitudes (including in Latvia) tomatoes are grown in greenhouses $[17,18]$.

The measurements were carried out in the autumn of 2017 in the greenhouse of Mezvidi, Latgalia, for three variants: tomato variety orange Bolzano F1 grown under 1) high-pressure sodium lamps (HPS) Master Green Power CG 230V 400W (PPF $725 \mu \mathrm{mol}^{-1}$ ) and 2) LED sources GreenPower DR/B LB 400V 190W (PPF $440 \mu \mathrm{mol}^{-1}$ ) and the 3) red Encore F1 grown under HPS. Illumination at the level of the tops of plants in all cases was 15000 Lx (Fig. 1).

Leaves of tomato are odd-pinnate, dissected into more or less number of leaflets; there are very small lobe and lobules between the leaflets. The leaf stalk, the length of which is different in early and late ripening, is long, passes into the main vein of the leaf and ends with the leaf apex. From the main vein of the leaf, lobes (sides) of the lobe and lobules of the leaf, more or less symmetrically divided by the central nerve of lobes and lobules, leave in pairs. The leaf shares (two to four pairs) for some varieties are often placed and overlap one another (thickened leaf type), for others the leaf type is sparse. The shape of the leaf is the most variable morphological feature [19].

The leaf is formed as a result of regular division and stretching of cells, and the change in its shape and complexity depends on the direction of cell divisions controlled by phytohormones. Sometimes climatic factors stimulate abnormal development of leaves, then new shoots appear on them. The colour of the leaves is related to the presence, absence or different concentration of pigments in epidermal and mesophilic cells. 
Two bilateral traits were subjected to statistical analysis: I) the lengths of the liflets, first from the apex of leaves of a complex leaf of tomato on the left and on the right $L_{L}$ and $L_{R}$ ); II) the content of chlorophyll in them $\left(C_{L}\right.$ and $\left.C_{R}\right)$.
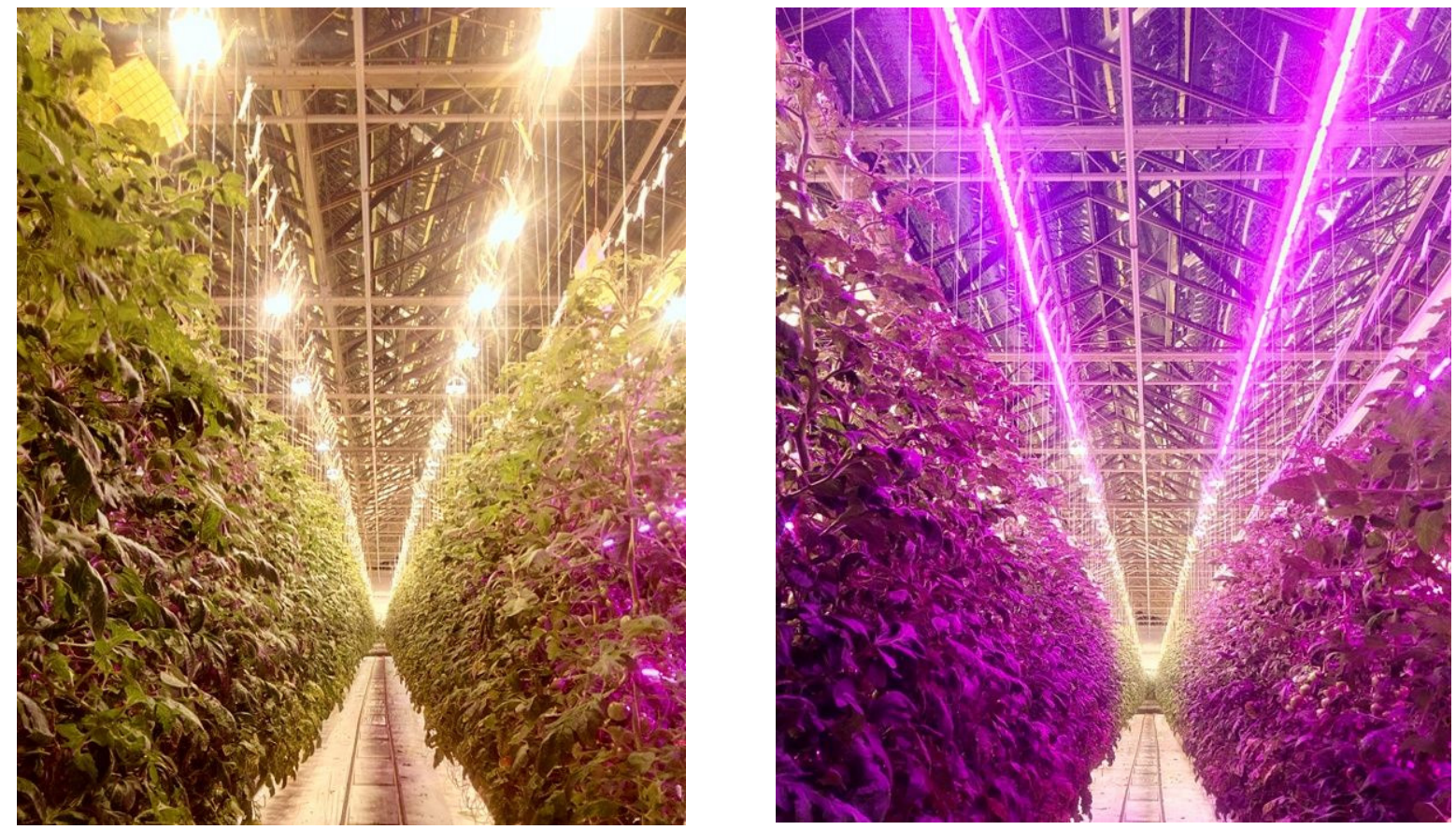

Fig. 1. Tomato plants in greenhouse under HPS (left) and LED (right) sources

The lengths of the leaflets were determined using a transparent measuring ruler (the division value is $1 \mathrm{~mm}$ ), laying it on a leaf along the vein of leaflets. The results were recorded with an accuracy of $0.5 \mathrm{~mm}$. For non-destructive determination of chlorophyll a Chlorophyll Content Meter CCM-200 was used (Fig. 2).
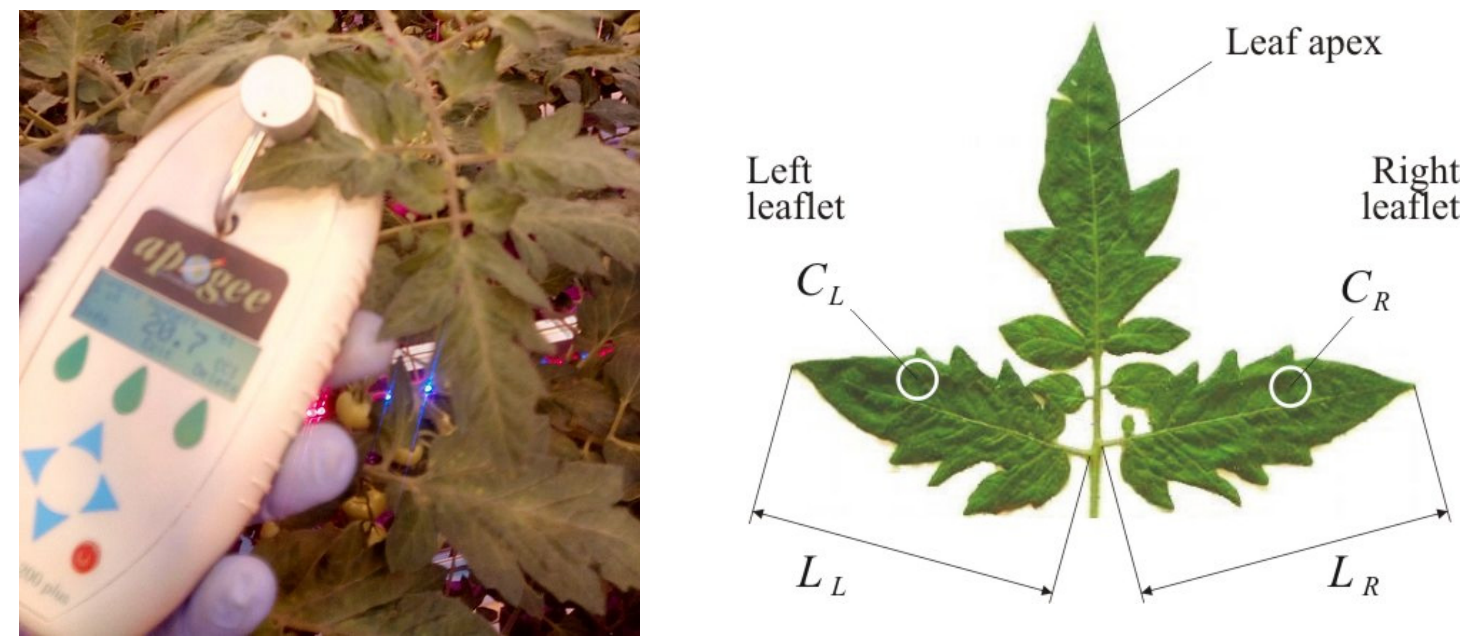

Fig. 2. Measurement of chlorophyll content index in leaf with CCM-200 (left) and bilateral traits of tomato leaf (right)

To determine the relative content of chlorophyll, its optical properties are taken into account, consisting in a significant absorption of light in the blue and red spectral bands. There is no absorption in the green and infrared ranges. Radiation is used at two wavelengths. At a wavelength of $653 \mathrm{~nm}$, the absorption of the light passing through the leaf depends on the concentration of chlorophyll. Radiation with a wavelength of $931 \mathrm{~nm}$ is used to compensate for the effect of leaf thickness. The meter determines the optical density at both wavelengths and calculates the chlorophyll content index (CCI) in the leaf by the formula 


$$
C=\frac{\tau_{931}}{\tau_{653}}
$$

where $\tau-$ transmittance at the appropriate wavelengths.

In this case, the absolute content of chlorophyll per unit area is not calculated. This requires calibration of the instrument by performing a standard biochemical analysis [20]

The values of the FA level for the bilateral trait $T$ (which was taken as $C$ and $L$ ) were calculated by the formula

$$
F A=\frac{1}{N} \sum_{i=1}^{N} \frac{\left|T_{L}^{i}-T_{R}^{i}\right|}{\left(T_{L}^{i}+T_{R}^{i}\right)},
$$

where $i$ - number of the plant;

$N$ - number of measurements.

The data were processed by mathematical statistics methods $(p<0.05)$ using Excel 2003 and Statistica 6.0 software packages. Statistical processing of the results of the assessment of the FA level included checking the data for the normal distribution of the difference between the bilateral traits; the presence of directed asymmetry and antisymmetry; on the dependence of the magnitude of the asymmetry of the trait from its size; comparison of the FA level in plants grown at different quality of irradiation.

\section{Results and discussion}

Statistical analysis of the distribution law of asymmetry values of bilateral traits, performed using the Kolmogorov-Smirnov, Shapiro-Wilk and Lilliefors consensus criteria, showed that the distribution pattern of the obtained samples differs from the normal one, so nonparametric methods of statistical analysis were used.

FA directivity testing was carried out using the Wilcoxon test. The analysis revealed fluctuations in the asymmetry of the trait around the zero mean, which is a diagnostic sign of the FA. Antisymmetry in the analyzed features is not revealed. For the comparability of the obtained results, the asymmetry is normalized to the size of the features.

An indicator of antisymmetry is the negative kurtosis of the distribution of differences between the sides $(L-R)$. For $k \geq 0$, the hypothesis about the fluctuating character of the asymmetry is accepted. The results of the analysis showed that there is no antisymmetry in the analyzed features.

It has been revealed that the influence of the type of the light source and tomato variety on FA on the basis of certain features is multidirectional (Fig. 3).
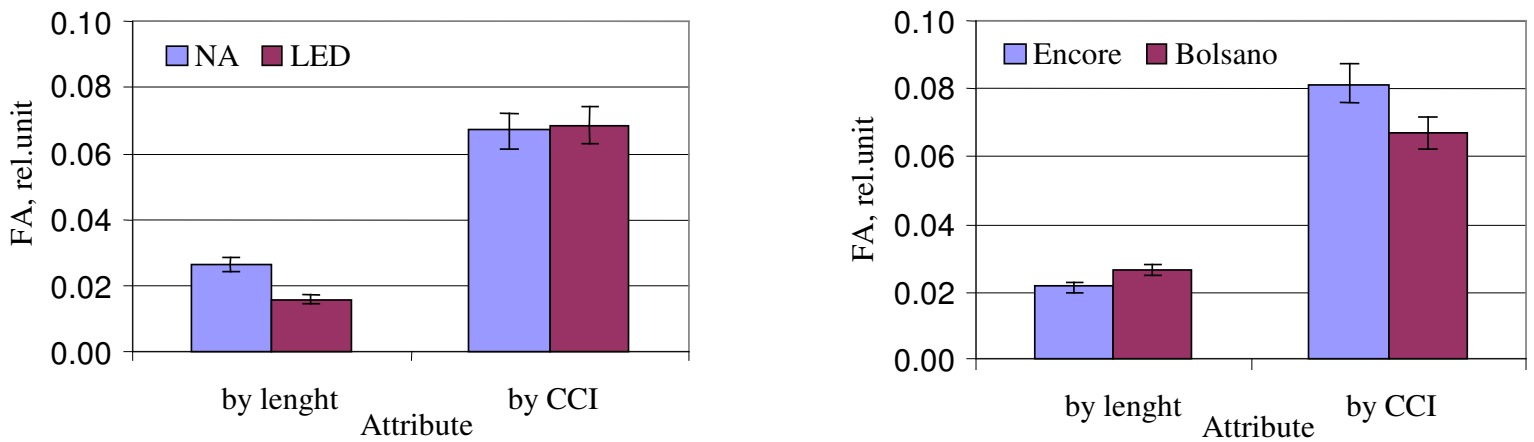

Fig. 3. Values of FA level calculated by length of leaflets and by chlorophyll content for different types of light sources (on the left) and tomato varieties (on the right)

The type of the light source had practically no effect on the FA level calculated by the chlorophyll content for the Bolzano tomato variety. However, for the same grade, the FA level by the leaflets length has a significant difference. Under the HPS for these two varieties, a greater difference in the FA level is observed for the chlorophyll content. For leaflets length these differences are smaller. 
Chlorophyll is the key biochemical component of the molecular apparatus providing the process of photosynthesis, in which the energy of light accumulates in the organic matter of plants. It is usually found in the thylakoids of chloroplasts and determines the effectiveness of photosynthesis, as well as the growth of plants and their adaptability to environmental conditions. The intensity of photosynthesis is affected by two types of factors: external factors, including lighting conditions; and internal, determined to a large extent by the chlorophyll content [21].

The chorophyll content in leaves varies depending on the genetics of plants, the content of mineral elements, environmental factors, etc [22]. The amount of chlorophyll is a direct indicator of the health and condition of plants. The acquisition of this value by non-destructive methods of analysis gives to researchers and agronomists very valuable diagnostic information. These data can be used for many purposes, such as nutrient assessment, irrigation management, pest management, environmental stress assessment, plant breeding [23]. Determination of the chlorophyll content by non-destructive methods is well developed for the main field crops, but these methods are also widely used to determine the content of chlorophyll in leafy vegetables. Our research has shown that the asymmetry of the chlorophyll content in symmetrical parts of the leaf of a tomato plant can serve as an assessment of the stability of its development.

It is known that the production of symmetrical parts in plants is preferred for at least two reasons. First, symmetry leads to the effective use of tissue for the production of a structure with a specific function. For example, if some leaves developed very asymmetrically, this could interfere with the solution of the problem of maximizing optimal lighting conditions for photosynthesis among all leaves of the plant. Thus, the form that most efficiently uses resources and gives the greatest benefits from pure fitness will often be the most symmetrical. Secondly, under natural conditions, leaf symmetry can lead to a uniform distribution of resistance to wind, and therefore asymmetric leaves can be more often damaged in strong winds [24]. Unfavourable environmental conditions affect both the FA level and the productivity of plants. Various traits of plants show a different character of the stability of development under environment impact. As a result of our experiments in industrial horticulture, the presence of a significant asymmetry of the bilateral structures of tomato leaves was detected by their size and chlorophyll content.

\section{Conclusions}

1. The fluctuating nature of the asymmetry of the bilateral traits of tomato leaflets by their length and chlorophyll content is proved.

2. For the tomato variety orange Bolzano F1 the FA level along the leaflets length is $66 \%$ higher under HPS compared to LED, and the chlorophyll content does not depend on the type of the light source.

3. Under HPS the FA level by the length of the leaflets is $24 \%$ higher in the Bolzano variety than in the red Encore F1 and in the chlorophyll content it is $28 \%$ lower.

\section{Acknowledgements}

Publication is created with support of European Regional Development Fund project "New control methods for energy and ecological efficiency increase of greenhouse plant lighting systems (uMOL)", Grant Agreement Nr. 1.1.1.1/16/A/261.

\section{References}

[1] Pérez B.S., Moreno A.D., García V.C. Influence of light on health-promoting phytochemicals of broccoli sprouts. Journal of the Science of Food and Agriculture, vol. 88, 2008, pp. 904-910.

[2] Козлов М.В. Исследования флуктуирующей асимметрии растений в России: мифология и методология (Investigations of fluctuating plant asymmetry in Russia: mythology and methodology). Экология, 2017, №1, pp.3-12. (In Russian).

[3] Alves-Silva E. The influence of Ditylenchus (Nematoda) galls and shade on the fluctuating asymmetry of Miconia fallax (Melastomataceae). Ecología Austral, vol. 22, 2012, pp. 53-61.

[4] Roy B.A., Stanton M.L. Asymmetry of wild mustard, Sinapsis arvensis (Brassicaceae), in response to severe physiological stresses. J. Evol. Biol., vol.12, 1999, pp. 440-449. 
[5] Avramov S., Pemac D., Tucić B. Phenotypic plasticity in response to an irradiance gradient in Iris pumila: adaptive value and evolutionary constraints. Plan. Ecol., vol. 190(2), 2007, pp. 275-290.

[6] Puerta-Pinero C., Gomez J. M., Hodar J. A. Shade and herbivory induce fluctuating asymmetry in a Mediterranean oak. International J. of Pl. Scien., vol. 169(5), 2008, pp. 631-635.

[7] Alves-Silva E., Del-Claro K. Effect of post-fire resprouting on leaf fluctuating asymmetry, extrafloral nectar quality, and ant-plant-herbivore interactions. Naturwissenschaften, vol. 100, 2013, pp. 525-532.

[8] Venâncio H., Alves-Silva E., Santos J.C. Leaf phenotypic variation and developmental instability in relation to different light regimes. Acta Botanica Brasilica, vol. 30(2), 2016, pp. 296-303.

[9] Ракутько С.А., Ракутько Е.Н., Маркова А.Е., Мишанов А.П.Флуктуирующая асимметрия билатеральных признаков как критерий оценки качества облучения в светокультуре (Fluctuating asymmetry of bilateral traits as a criterion for assessing the quality of irradiation in indoor plant lighting). Технологии и технические средства. 2017, № 91, pp. 45-55. (In Russian)

[10] Ракутько С.А., Васькин А.Н., Ракутько Е.Н. Статистический анализ флуктуирующей асимметрии билатеральных признаков листьев петрушки (Petroselinum Tuberosum) при выгонке под различным спектром излучения (Statistical analysis of the fluctuating asymmetry of bilateral traits of parsley leaves (Petroselinum Tuberosum) in forcing under a different light quality). Известия СПбГАУ, 2017, № 1 (46). pp. 253-260. (In Russian)

[11] Ракутько С.А., Ракутько Е.Н., Мишанов А.П., Маркова А.Е. Методика оценки стабильности развития растений в светокультуре по уровню флуктуирующей асимметрии билатеральных признаков (Method for assessing the stability of plant development in indoor plant lighting by the level of fluctuating asymmetry of bilateral traits. Международный журнал экспериментального образования, 2017, № 3(1). 74 p. (In Russian)

[12] Rakutko S., Rakutko E., Kaposhko D., Vaskin A. Influence of light quality on fluctuating asymmetry of bilateral traits of forced parsley leaves. Jelgava: Latvia University of Agriculture, Faculty of Engineering, 2017, pp. 42-47.

[13] Rakutko S., Rakutko E., Kaposhko D., Vaskin A. Monitoring technique of energy and ecological efficiency of indoor plant lighting. Jelgava: Latvia University of Agriculture, Faculty of Engineering, 2016, pp. 95-101.

[14] Lucier G., Lin B.H., Alsshouse J. etc. Factors affecting tomato consumption in the united states. ERS/USDA. Vegetables and Specialties/VGS-282/November, 2000.

[15] Hille J, Koornneef M, Ramanna M. etc. Tomato: a crop species amenable to improvement by cellular and molecular methods. Euphytica, vol. 42, 1989, pp. 1-23.

[16] Atherton J. G., Rudich J. The tomato crop. A scientific basis for improvement. - London, New York, 1986, $661 \mathrm{p}$.

[17] Boivin C., Gosselin A., Trudel M. J. Effects of supplementary lighting on transplant growth and yield of greenhouse tomato. HortScience, vol. 22(6), 1987, pp. 1266-168.

[18] McCall D. Effect of supplementary light on tomato transplant growth, and the after-effects on yield. Scientia Horticulturae. vol. 51, 1992, pp. 65-70.

[19] Holtan H.E., Hake S. Quantitative trait locus analysis of leaf dissection in tomato using Lycopersicon pennellii segmental introgression lines. Genetics, vol. 165, 2003, pp. 1541-1550.

[20] CCM-200plus. [online] [18.01.2018]. Available at: http://www.optisci.com/ccm-200.html.

[21] Лебедев С.И. Физиология растений (Plant Physiology). Moskow, Агропромиздат, 1988, 544 p. (In Russian)

[22] Haboudane D., John R., Millera J.R. etc. Integrated narrow-band vegetation indices for prediction of crop chlorophyll content for application to precision agriculture. Remote Sensing of Environment, vol. 81, 2002, pp. 416-426.

[23] Sims D.A., Gamon J.A. Relationships between leaf pigment content and spectral reflectance across a wide range of species, leaf structures and developmental stages. Remote Sensing of Environment, vol. 81(2-3), 2002, pp. 337-354.

[24] Schlichting C.D. The evolution of phenotypic plasticity in plants. Annual Review of Ecology and Systematics, vol.17, 1986, pp. 667-693. 